\title{
Optimization of Wire Electro Discharge Machining of HCHCr Material using Taguchi Methodology
}

Kranti Kumar Bhosale ${ }^{1}$, Vishal Mane ${ }^{2}$, Vivek Chavan ${ }^{3}$, Amit Kumar Jagadale ${ }^{4}$, Virendra Bhagvat

Assistant Professor, Mechanical Engineering Department, Dr. Daulatrao Aher College of Engineering, Karad, India Research Assistant, M.S. Industrial Engineering, Iowa State University, Ames, Iowa, USA ${ }^{2}$

Assistant Professor, Mechanical Engineering Department, Dnyanshree Institute of Engineering \& Technology,

\author{
Satara, India ${ }^{3}$
}

\begin{abstract}
In this paper, the cutting of High Carbon High Chromium (HCHCr) material using Wire electro discharge machining (WEDM) with a brass wire by using Taguchi methodology has been reported. The Taguchi method is used to formulate the experimental layout, to analyze the effect of each parameter on the machining characteristics, and to predict the optimal choice for each WEDM parameter such as Pulse on time, Pulse off time, feed, Sensitivity. It is found that these parameters have a significant influence on machining characteristic such as material removal rate (MRR), Overcut (OC) and Surface Roughness (Ra). The analysis using Taguchi method reveals that, in general the feed and sensitivity significantly affects the MRR and Pulse on time and Pulse off time has the favorable effect on the Ra.
\end{abstract}

Keywords: WEDM, Taguchi method, $\mathrm{HCHCr}$, material removal rate, Overcut and Surface roughness.

\section{INTRODUCTION}

Wire Electrical Discharge Machining or WEDM is a machining method primarily used for hard metals or those that would be impossible to machine with traditional techniques. The non-contact machining technique has been continuously evolving from a mere tool and dies making process to a micro-scale application machining alternative attracting a significant amount of research interests.

One critical limitation, however, is that WEDM only works with materials that are electrically conductive. WEDM is especially well-suited for cutting intricate contours or delicate cavities that would be difficult to produce with a grinder, an end mill or other cutting tools. Metals that can be machined with WEDM include hardened tool-steel, titanium and carbide etc.

\section{NEED FOR WIRE ELECTRIC DISCHARGE MACHINING (WEDM)}

Among all the non-traditional machining processes, WEDM has some advantages that make its acceptability over other machining options.

\section{Advantages}

- It has ability to create complex and intricate parts with a high degree of accuracy.

- This process is able to machine hard materials that other machining processes would have difficulties.
Another advantage of WEDM is its ability to machine parts on an extremely small scale.

- While using this process, the workpiece is not deformed from impact because there is no direct contact between the electrode and the material.

- The work piece is burr-free after completion and saved from heat damage because very little is actually generated during the procedure that would harm the material.

\section{Disadvantages}

- WEDM is low Material Removal Rate.

- Limited to electrical conductive materials only.

\section{WORKING PRINCIPLE OF WEDM}

In wire EDM a very thin wire serves as the electrode. Special brass wires are typically used; the wire is slowly fed through the material and the electrical discharges actually cut the workpiece. Wire EDM is usually performed in a bath of water. The wire itself does not actually touch the metal to be cut; the electrical discharges actually remove small amounts of material and allow the wire to be moved through the workpiece. When the distance between the two electrodes is reduced, the intensity of the electric field in the volume between the electrodes becomes greater than the strength of the dielectric (at least in some point), which breaks, 
IARJSET

allowing current to flow between the two electrodes. permits the spark to jump the gap between the electrode This phenomenon is the same as the breakdown of a and the work piece through the dielectric fluid. Intense capacitor (condenser). As a result, material is removed heat is created in the localized area of the spark impact, from both the electrodes.

\section{EXPERIMENTAL PROCESS OF WEDM}

\section{The basic processes of WEDM}

Voltage and amperage control spark between wire electrodes

- Demonized dielectric fluid surrounds wire electrode and work piece.

- Dielectric fluid acts as resistor until enough voltage is applied then fluid ionizes and spark melts and vaporizes the material.

- Once sparking process is completed workpiece material is cooled by dielectric fluid.

- Melted work piece material forms in WEDM chips. A filter then removes chips and dielectric fluid is reused.

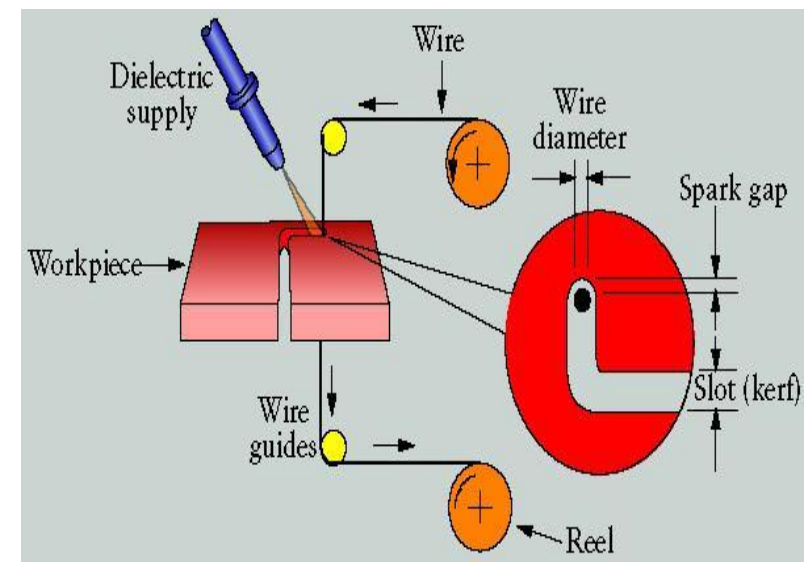

Figure 1: Experimental Setup

EDM oil was used as a dielectric fluid in this experiment. Diameter of electrode and thickness of work piece is measured by digimatic micrometer. (Make: Mitutoyo, Least count: $0.001 \mathrm{~mm}$ ). Weight of work piece is measured by Precisa-make weighing machine (Accuracy: $0.1 \mathrm{mg}$ ).

\section{Principle of WEDM}

Wire electric discharge machining is a controlled metal removing technique whereby an electric spark is used to cut the work piece, which takes a shape according to the path given by software. The electrode (Wire) is made from electrically conductive material (used Brass Wire). The work piece and wire are both in continuous flow of a dielectric fluid. Dielectric fluid should be nonconductor of electricity. A servo mechanism maintains a gap of about 0.01 to $0.02 \mathrm{~mm}$ between the electrode \& the work piece, preventing them from coming into contact with each other. A direct current of low voltage \& high amperage is delivered to the electrode. These electrical energy impulses vaporize the oil at this point. This the metal melts and a small particle of molten metal is expelled from the surface of the workpiece. The dielectric fluid which is constantly being circulated carries away the eroded particles of metal during the off cycle of the pulse and also assists in dissipating the heat caused by the spark.

\section{Work piece Material}

$\mathrm{HCHCr}$ material is used as work piece material in this research work.

Table 1: Material Properties of $\mathrm{HCHCr}$

\begin{tabular}{|c|c|c|}
\hline $\begin{array}{c}\text { Sr. } \\
\text { No. }\end{array}$ & Parameter & Value \\
\hline 01 & Ultimate Tensile Strength (Psi) & $1,35,000$ \\
\hline 02 & Hardness Rockwell & 60 \\
\hline 03 & Elongation $(\%)$ & 45 \\
\hline 04 & Density $(\mathrm{Kg} / \mathrm{cu} \mathrm{m})$ & 8220 \\
\hline 05 & Melting Range $\left({ }^{0} \mathrm{~F}\right)$ & 2200 to 2450 \\
\hline
\end{tabular}
Input Factors
1) Pulse on time (Ton)
2) Pulse off time (Toff)
3) Feed (f)
4) Sensitivity (Sen)

\section{Responses Measured}

1) Material Removal Rate (MRR)

2) Overcut (OC)

3) Surface roughness $(\mathrm{Ra})$

EDM oil was used as a dielectric fluid in this experiment. Diameter of electrode and thickness of work piece is measured by digimatic micrometer. (Make: Mitutoyo, Least count: $0.001 \mathrm{~mm})$. Weight of work piece is measured by Precisa make weighing machine (Accuracy: $0.1 \mathrm{mg})$.

\section{DESIGN OF EXPERIMENTS}

Taguchi Method

Taguchi methods are the most recent additions to the toolkit of design, process and manufacturing engineers, and quality assurance experts. In contrast to statistical process control, which attempts to control the factors that adversely affect the quality of production, Taguchi methods focus on design - the development of superior performance designs (of products and manufacturing processes) to deliver quality.

An experimental design scheme of statistical experiments that uses orthogonal arrays however entails the following considerations and consequences

1) The orthogonal array leads only to a main effect design. Use of an orthogonal array forces the investigator 
IARJSET

International Advanced Research Journal in Science, Engineering and Technology

National Conference on Design, Manufacturing, Energy \& Thermal Engineering (NCDMETE-2017)

AGTI's Dr. Daulatrao Aher College Engineering, Vidyanagar Extension, Karad

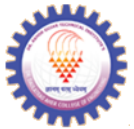

Vol. 4, Special Issue 1, January 2017

to assume that the response one observe can be experiments have to be carried out as the number of the approximated by an additive function, separable into the process parameters increases. To solve this important task, effects of the individual (main) control factors under the Taguchi method uses a special design of orthogonal study. One assumes no other effects, in particular no array to study the entire parameter space with only a interactions, to be present. A verification experiment can small number of experiments. The experimental results later verify whether this approximation is satisfactory and are then transformed into a signal-to-noise (S/N) ratio. a valid one.

The $\mathrm{S} / \mathrm{N}$ ratio can be used to measure the deviation of the 2) The columns of the orthogonal arrays are pair-wise performance characteristics from the desired values. orthogonal. In every pair of columns, all combinations of Usually, there are three categories of performance the levels of each (independent) factor under study occur characteristics in the analysis of the S/N ratio and they do so equal number of times.

3) It follows from no. 2 that the main effect estimates of all factors and their associated sum of squares are independent under the assumption of normality and equality of observation variance. Hence the significance test (ANOVA) for these factors is independent.

4) When orthogonal array guides the experiments, one computes the main factor effect. These computed effect may be then used to predict the response for any combination of factor treatments, because one assumes that these effects are separable and additive. The variance of the prediction error (caused by factors not controlled in the experiments and the exclusion of interactions) is the same for all such treatment combinations.

5) Factors which are studied may be discrete or continuous. For continuous factors it is possible to break down main effects of three level factors into linear and quadratic terms.

A non-linear effect may sometimes be useful in fine tuning and improving the initial design.

6) In the initial stages of optimization, one may limit the investigation to the study of main effect. Later on, it is possible to run larger orthogonally designed experiments to study interaction effects also, if necessary. Taguchi aimed at making the design robust first, followed by an adjustment to put performance at desired target. The task begins by recognizing the different factors influencing performance belong to two distinct categories

- Design parameter: It is the distinct and intrinsic features of the process or the product that influence and determine its performance.

- Noise factor: It is the factor that is either too hard or uneconomical to control, even though this may cause unwanted variation in performance.

If one seeks to maximize a performance aspect or minimize it, variations to the loss function form are available. If the performance characteristic y happens to be such that the smaller it is the better, then the loss can be expressed by the expression

$$
\mathrm{L}(\mathrm{y})=\mathrm{k} \cdot \mathrm{y}^{2}
$$

On the other hand if the performance characteristic is such that the larger it is better, then:

$$
\mathrm{L}(\mathrm{y})=\mathrm{k} \cdot\left(1 / \mathrm{y}^{2}\right)
$$

\section{- Signal to Noise Ratio}

Classical experimental design methods are too complex and not easy to use. Furthermore a large number of

- lower-the-better,

- higher-the-better,

- nominal-the-better

\section{DESIGN OF EXPERIMENT FOR WEDM OF HCHCR MATERIAL}

The design of experiment (D.O.E.) chosen for the electric discharge machining of $\mathrm{HCHCr}$ was a Taguchi L9 orthogonal array, by carrying out a total number of 9 experiments along with 4 verification experiments (optional).

\section{- L9 Orthogonal Array}

L9 $\left(\right.$ In $3^{4}$ ) array 9 rows represent the 9 experiment to be conducted with 4 columns at, 3 levels of the corresponding factor. The matrix form of these arrays is shown in table 3.1 , where $1,2,3$ in the table represents the level of each parameter.

Table 3: Level of each parameter

\begin{tabular}{|c|c|c|c|c|}
\hline \multirow{2}{*}{ Sr. No. } & \multirow{2}{*}{ Factors } & \multicolumn{3}{|c|}{ Levels } \\
\cline { 3 - 5 } & & $\mathbf{1}$ & $\mathbf{2}$ & $\mathbf{3}$ \\
\hline 1 & Ton $(\mu \mathrm{s})$ & 31 & 32 & 33 \\
\hline 2 & Toff $(\mu \mathrm{s})$ & 6 & 7 & 8 \\
\hline 3 & Feed $(\mathrm{mm} / \mathrm{min})$ & 80 & 90 & 100 \\
\hline 4 & Sensitivity & 8 & 9 & 10 \\
\hline
\end{tabular}

Based on the Taguchi L9 orthogonal array, the values of input factors are placed in the design matrix and it is shown in Table 4

Table 4: L9 Design Matrix

\begin{tabular}{|c|c|c|c|c|}
\hline $\begin{array}{c}\text { Experiment } \\
\text { No. }\end{array}$ & $\begin{array}{c}\mathrm{T}_{\text {on }} \\
(\mathrm{sec})\end{array}$ & $\begin{array}{c}\mathrm{T}_{\text {off }} \\
(\mathrm{sec})\end{array}$ & $\begin{array}{c}\text { Feed } \\
(\mathrm{mm} / \mathrm{min})\end{array}$ & Sensitivity \\
\hline E1 & 31 & 6 & 80 & 8 \\
\hline E2 & 31 & 7 & 90 & 9 \\
\hline E3 & 31 & 8 & 100 & 10 \\
\hline E4 & 32 & 6 & 90 & 10 \\
\hline E5 & 32 & 7 & 100 & 8 \\
\hline E6 & 32 & 8 & 80 & 9 \\
\hline E7 & 33 & 6 & 100 & 9 \\
\hline E8 & 33 & 7 & 80 & 10 \\
\hline E9 & 33 & 8 & 90 & 8 \\
\hline
\end{tabular}


IARJSET

International Advanced Research Journal in Science, Engineering and Technology

National Conference on Design, Manufacturing, Energy \& Thermal Engineering (NCDMETE-2017) AGTI's Dr. Daulatrao Aher College Engineering, Vidyanagar Extension, Karad

Vol. 4, Special Issue 1, January 2017

Table 5: Experimental Results \& Calculation of Various Response Factors based on Taguchi L9 Orthogonal Array

\begin{tabular}{|c|c|c|c|}
\hline Experiment No & MRR $(\mathrm{gm} / \mathrm{min})$ & OC $(\mathrm{mm})$ & $\mathrm{Ra}(\mu)$ \\
\hline E1 & 1.4 & 0.436 & 3.27 \\
\hline E2 & 1.27 & 0.431 & 3.5 \\
\hline E3 & 1.22 & 0.431 & 3.74 \\
\hline E4 & 1.56 & 0.414 & 3.32 \\
\hline E5 & 1.38 & 0.441 & 3.58 \\
\hline E6 & 1.25 & 0.42 & 3.61 \\
\hline E7 & 1.6 & 0.414 & 3.49 \\
\hline E8 & 1.38 & 0.417 & 3.57 \\
\hline E9 & 1.21 & 0.49 & 4.02 \\
\hline
\end{tabular}

Where $\mathrm{MRR}=$ Weight/time, $\mathrm{OC}=$ Size of slot - Size of removed part.

- Analysis on Experimental Data

After the experimental procedure, different response factors like material removal rate (MRR), Overcut (OC), Surface roughness ( $\mathrm{Ra}$ ) of cut section were calculated from the observed data. Then a statistical analysis was performed on the calculated values and the signal to noise ratio values of four response factors are tabulated in Table 5.1 shown in next page.

- Effect of Input Factors on Material Removal Rate (MRR)

The response table for signal to noise ratio for material removal rate (MRR) is shown in Table 7 and the corresponding analysis of variance (ANOVA) table is shown in Table 8 for material removal rate (MRR), the calculation of $\mathrm{S} / \mathrm{N}$ ratio follows "Larger the Better" model.

- Effect of Input Factors on Surface Roughness

The response table for signal to noise ratio for Surface roughness $(\mathrm{Ra})$ is shown in Table 11 and the corresponding analysis of variance (ANOVA) table is shown in Table 12. For radial overcut (ROC), the calculation of $\mathrm{S} / \mathrm{N}$ ratio follows "Smaller the Better" model. So Pulse-off time ( $\left.\mathrm{T}_{\text {off }}\right) \&$ Pulse-on time $\left(\mathrm{T}_{\text {on }}\right)$ has the maximum effect on radial overcut. Feed (f) and Sensitivity (Sen) has less effect on Surface Roughness (Ra).

Table 6: Calculation of Signal to Noise ratio for Various Response Factors

\begin{tabular}{|c|c|c|c|}
\hline $\begin{array}{c}\text { Experiment } \\
\text { No. }\end{array}$ & $\begin{array}{c}\text { S/N Ratio for } \\
\text { MRR }\end{array}$ & $\begin{array}{c}\text { S/N Ratio for } \\
\text { OC }\end{array}$ & $\begin{array}{c}\text { S/N Ratio for } \\
\text { Ra }\end{array}$ \\
\hline E1 & 2.92 & 7.21 & -10.29 \\
\hline E2 & 2.73 & 7.31 & -10.88 \\
\hline E3 & 2.14 & 7.31 & -11.46 \\
\hline E4 & 3.86 & 7.66 & -10.42 \\
\hline
\end{tabular}

\begin{tabular}{|c|c|c|c|}
\hline E5 & 2.79 & 7.11 & -11.08 \\
\hline E6 & 1.94 & 7.54 & -11.15 \\
\hline E7 & 4.08 & 7.66 & -10.86 \\
\hline E8 & 2.79 & 7.6 & -11.05 \\
\hline E9 & 1.65 & 6.2 & -12.08 \\
\hline
\end{tabular}

Table 7: Response Table for Signal to Noise Ratios for MRR

\begin{tabular}{|c|c|c|c|c|}
\hline Level & $\begin{array}{c}\text { Pulse-on } \\
\text { Time Ton }\end{array}$ & $\begin{array}{c}\text { Pulse-off } \\
\text { Time Toff }\end{array}$ & Feed f & $\begin{array}{c}\text { Sensitivity } \\
\text { Sen }\end{array}$ \\
\hline 1 & 2.597 & 3.62 & 2.550 & 2.453 \\
\hline 2 & 2.863 & 2.77 & 2.747 & 2.917 \\
\hline 3 & 2.840 & 1.91 & 3.000 & 2.930 \\
\hline Delta & 0.266 & 1.71 & 0.450 & 0.477 \\
\hline Rank & 4 & 1 & 3 & 2 \\
\hline
\end{tabular}

Table 8: Analysis Of Variance (ANOVA) for MRR

\begin{tabular}{|c|c|c|c|c|}
\hline Sources & D.O.F & $\begin{array}{c}\text { Sum } \\
\text { of differences } \\
\text { of } \\
\text { squares }\end{array}$ & $\begin{array}{c}\text { Mean } \\
\text { square }\end{array}$ & $\begin{array}{c}\% \\
\text { contribution }\end{array}$ \\
\hline $\mathrm{T}_{\text {on }}$ & 2 & 0.1303 & 0.065 & 2.47 \\
\hline $\mathrm{T}_{\text {off }}$ & 2 & 4.3862 & 2.1931 & 83.32 \\
\hline $\mathrm{f}$ & 2 & 0.3053 & 0.1526 & 5.77 \\
\hline Sen & 2 & 0.4430 & 0.2215 & 8.44 \\
\hline Total & 8 & 5.2648 & - & - \\
\hline
\end{tabular}

So Pulse-off time ( $\mathrm{T}_{\mathrm{Off}}$ ) and Sensitivity (Sen) have the maximum effect on material removal rate whereas pulse-on time $\left(\mathrm{T}_{\mathrm{On}}\right)$ and Feed (f) have less effect.

- Effect of Input Factors on Overcut

The response table for signal to noise ratio for Overcut is shown in Table 9 and the corresponding analysis of variance (ANOVA) table is shown in Table 10. For Overcut, the calculation of $\mathrm{S} / \mathrm{N}$ ratio follows "Smaller the Better" model.

So Sensitivity (Sen) has the maximum effect on overcut and Pulse-off time ( $\mathrm{T}_{\mathrm{Off}}$ ) also has some influence on it whereas Feed (f) and Pulse-on time ( $\left.\mathrm{T}_{\mathrm{On}}\right)$ have much less effect on overcut.

Table 9: Response Table for Signal to Noise Ratios for $\mathrm{OC}$

\begin{tabular}{|c|c|c|c|c|}
\hline Level & $\begin{array}{c}\text { Pulse-on } \\
\text { Time Ton }\end{array}$ & $\begin{array}{c}\text { Pulse-off } \\
\text { Time Toff }\end{array}$ & $\begin{array}{c}\text { Feed } \\
\mathbf{f}\end{array}$ & $\begin{array}{c}\text { Sensitivity } \\
\text { Sen }\end{array}$ \\
\hline 1. & 7.277 & 7.510 & 7.450 & 6.840 \\
\hline 2. & 7.440 & 7.340 & 7.060 & 7.503 \\
\hline 3. & 7.153 & 7.020 & 7.360 & 7.523 \\
\hline Delta & 0.284 & 0.490 & 0.390 & 0.683 \\
\hline Rank & 4 & 2 & 3 & 1 \\
\hline
\end{tabular}


IARJSET

International Advanced Research Journal in Science, Engineering and Technology

National Conference on Design, Manufacturing, Energy \& Thermal Engineering (NCDMETE-2017)

AGTI's Dr. Daulatrao Aher College Engineering, Vidyanagar Extension, Karad

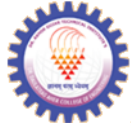

Vol. 4, Special Issue 1, January 2017

- Verification experiment

After performing the statistical analysis on the experimental data, it has been observed that there is one particular level for each factor for which the responses are either maximum (in case of MRR) or minimum (in case of $\mathrm{OC}$ and $\mathrm{Ra}$ ). The signal to noise ratio $(\mathrm{S} / \mathrm{N}$ ratio) of each responses corresponding to each factor level also has a maximum and a minimum value. So for finding the optimum parameter setting for each response factors, the additive model of Taguchi method is used. S/N ratio is calculated based on the formula containing negative of logarithmic value, which is a monotonic decreasing function. So $\mathrm{S} / \mathrm{N}$ ratio should be always kept at maximum value. Therefore in finding the optimum parameter setting, the levels of input factors are chosen in such a way that the $\mathrm{S} / \mathrm{N}$ ratios for those levels have maximum values (for each input factor). There are three optimum parameter settings corresponding to the three response factors. The combination of input factor levels, for which optimum settings will be obtained, is given in Table 11.

Using these three optimum parameter settings, three verification experiments has been carried out and the experimental results are shown in Table 11.

Table 10: Optimal Parameter Settings of Input Factors

\begin{tabular}{|c|c|c|c|c|}
\hline \multirow{2}{*}{$\begin{array}{c}\text { Physical } \\
\text { Requirement }\end{array}$} & \multicolumn{4}{|c|}{ Optimal Combination } \\
\cline { 2 - 5 } & $\mathbf{T}_{\text {ON }}$ & $\mathbf{T}_{\text {OFF }}$ & feed & Sensitivity \\
\hline $\begin{array}{c}\text { Maximum } \\
\text { MRR }\end{array}$ & 32 & 6 & 100 & 10 \\
\hline $\begin{array}{c}\text { Minimum } \\
\text { OC }\end{array}$ & 32 & 6 & 80 & 10 \\
\hline $\begin{array}{c}\text { Minimum } \\
\text { RC }\end{array}$ & 31 & 6 & 80 & 9 \\
\hline
\end{tabular}

Table 11: Verification Experimental Results \& Calculation of Various Response Factors.

\begin{tabular}{|l|l|l|l|}
\hline Verification Exp. for & MRR & \multicolumn{1}{c|}{ OC } & \multicolumn{1}{c|}{ Ra } \\
\hline Max. MRR & 1.82 & 0.404 & 2.93 \\
\hline Min. OC & 1.53 & 0.296 & 3.16 \\
\hline Min. Ra & 1.65 & 0.331 & 2.31 \\
\hline
\end{tabular}

\section{DISCUSSION}

A. Effect of Input Factors on Material Removal Rate (MRR)

From figure 6 , it is observed that increased pulse-on time $\left(\mathrm{T}_{\mathrm{On}}\right)$ for certain limit i.e. $(31 \mu \mathrm{s}$ to $32 \mu \mathrm{s})$ causes higher MRR, which is also theoretically established. But an again increase of pulse-on time ( $\left.\mathrm{T}_{\mathrm{On}}\right)$ from $32 \mu$ s to 33 $\mu$ s results in lower MRR. This is due to fact that here no interaction of input factors has been considered, although some interaction effect may be present there.

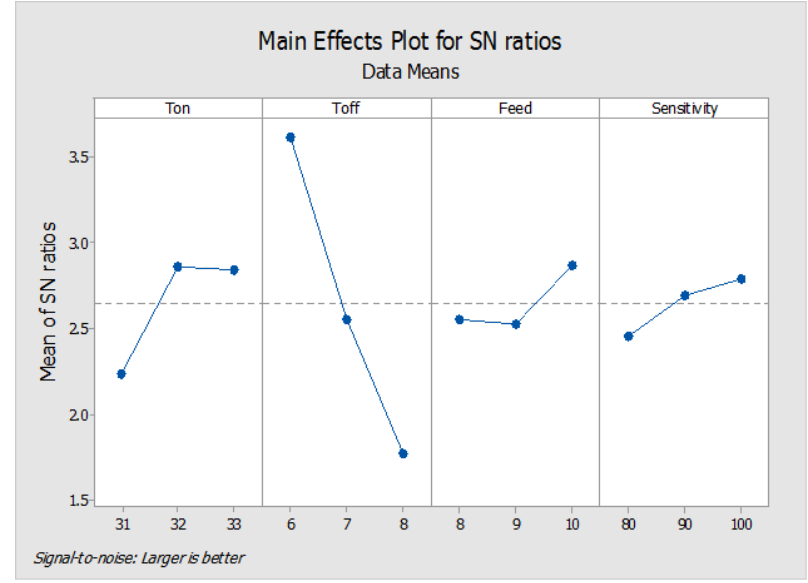

Fig. 6. S/N Ratio Curve for MMR

B. Effect of Input Factors on Overcut (OC)

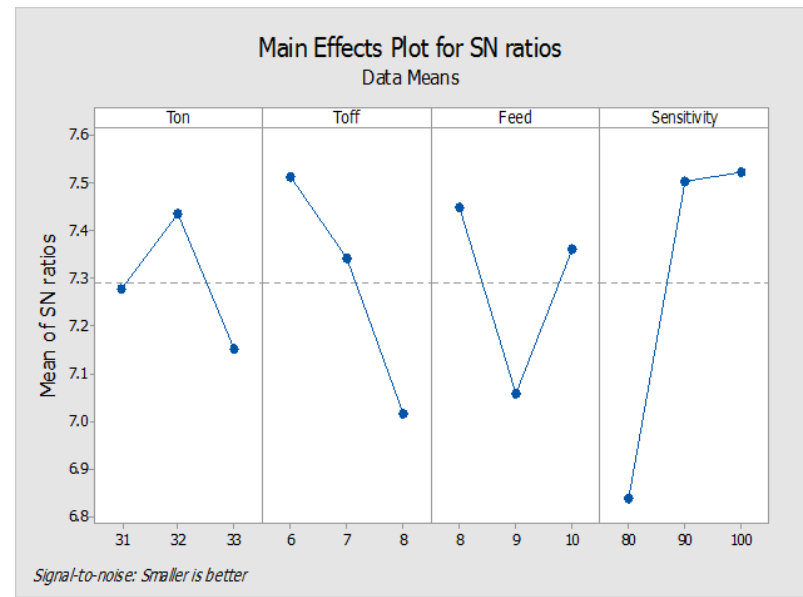

Fig. 7. S/N Ratio Curve for OC

From the Figure 7 , it is observed that $\mathrm{S} / \mathrm{N}$ ratio curve for overcut (OC) has an increasing trend with increase of pulse-on time ( $\mathrm{T}_{\mathrm{on}}$ ) up to certain limit i.e. from $31 \mu \mathrm{s}$ to $32 \mu \mathrm{s}$ and thendecreased suddenly for $33 \mu \mathrm{s}$.

C. Effect of Input Factors on Surface Roughness (Ra)

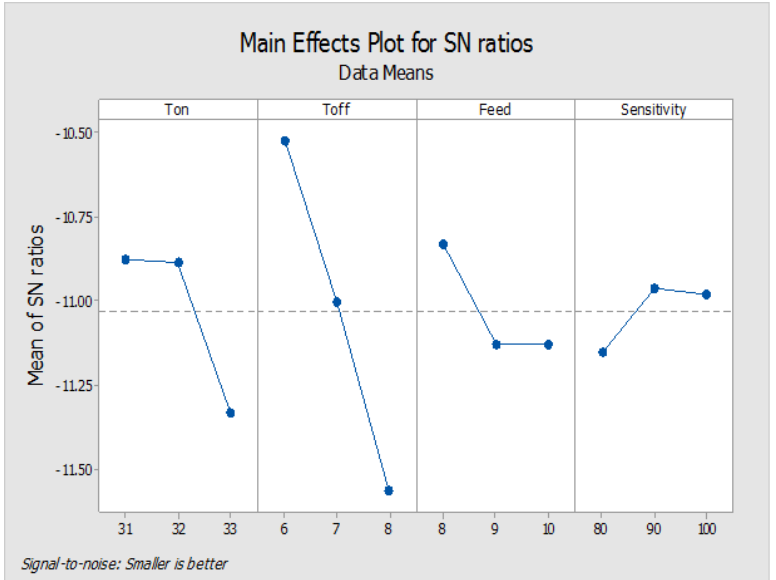

Fig. 8: S/N Ratio Curve for Ra. 
IARJSET

From figure 8 , it is observed that $\mathrm{S} / \mathrm{N}$ ratio curve for Surface roughness has an decreasing trend of Ton for $31 \mu \mathrm{s}$ to $32 \mu \mathrm{s}$ and then decreases suddenly for $32 \mu \mathrm{s}$ to $33 \mu \mathrm{s}$.

\section{DISCUSSION ON VERIFICATION EXPERIMENT}

From Table 11, it has been observed that the prediction errors for material removal rate (MRR), Overcut (OC) and Surface Roughness ( $\mathrm{Ra}$ ) are within the acceptable range. Hence the additive model is valid for these optimum parameter settings. So it can be concluded that the combinations of parameters tend to reach towards optimum settings.

\section{CONCLUSION}

Increased pulse-on time and Feed causes higher MRR, which is also theoretically established. Pulse off time and sensitivity cause relatively less effect on MRR. S/N ratio curve for overcut (OC) has an increasing trend with increase of pulse-on time ( $\left.\mathrm{T}_{\mathrm{On}}\right)$ up to certain limit and then decreases so Pulse on time and Pulse off time having favorable effect on Overcut. Surface roughness is mainly influenced by the sensitivity. Other three factors having favorable effect on Ra. Taguchi L9 orthogonal matrix experiment, no interactions between the input factors are considered. But some interaction effect may be present during the experiment. This may result in some observations which do not go with the theoretical belief. Some portion of the material is conductive and some portion is non-conductive. But WEDM requires conductive workpiece. So the composite properties of the workpiece may also lead to some observations which contradict the theoretical belief.

\section{REFERENCES}

[1] S. S. Mahapatra and Amar Pataki, "Optimization of wire electrical discharge machining (WEDM) process parameters using Taguchi method", International Journal of Advance Manufacturing Technology. P.1-15

[2] Jatinder Kapoor, Sehijpal Singh, Jaimal Singh Khamba. "Recent Developments in Wire Electrodes for High Performance WEDM", Proceedings of the World Congress on Engineering,Vol. II,June 30 - July 2, 2010, London, U.K.

[3] Muthu Kumar, Suresh Babu, Venkatasamy and Raajenthiren. "Optimization of the WEDM Parameters on Machining Incoloy 800 Super alloy with Multiple Quality Characteristics" International Journal of Engineering Science and Technology Vol. 2(6), 2010, 1538-1547.

[4] Pujari S. Rao and Koona Ramji, "Effect of WEDM conditions on surface roughness: A Prapmetric Optimisation using Taguchi method", International Journal of Advanced Engineering Sciences and Technologies Vol No. 6, Issue No. 1, 041 - 048 .

[5] Y. M. Puri and N. V. Deshpande "Simultaneous Optimization of multiple quality characteristics of WEDM based on fuzzy logic and Taguchi technique" Mechanical Engineering, VNIT, Nagpur, India.ympuri@yahoo.co.in

[6] Sorana D. Bolboacă Lorentz Jäntschi, "Design of Experiments: Useful Orthogonal Arrays for number of experiments from 4 to 16". ISSN $1099-4300$ (C) 2007 by MDPI.
[7] Saurav Datta, Siba Sankar Mahapatra, "Modeling, simulation and parametric optimization of wire EDM process using response surface methodology coupled with grey-Taguchi technique" International Journal of Engineering, Science and Technology Vol. 2, No. 5, 2010, pp. 162-183.

[8] Pujari S. Rao, Koona Ramji, Beela S., "Prediction of Material removal rate for Aluminum BIS-24345 Alloy in wire-cut EDM" International Journal of Engineering Science and Technology Vol. 2 (12), 2010, 7729-7739.

[9] H. Singh, R. Garg, "Effects of process parameters on material removal rate in WED." Journal of Achievements in Materials and Manufacturing Engineering, vol. 32, Issue 1. 